\title{
FORMULATION AND DEVELOPMENT OF SUSTAINED RELEASED GLICLAZIDE TABLETS WITH THE DIFFERENT HYDROPHILIC POLYMER BY USING DIRECT COMPRESSION TECHNIQUE
}

Sonali Agarkar ${ }^{1}$

1Department of Pharmaceutical Sciences and Technology, Institute of Chemical Technology, Matunga, Mumbai-400019, Maharashtra, India

\begin{abstract}
:
To effectively manage the diabetic mellitus type-II hyperglycemic problem, Gliclazide tablet is the sustainedrelease tablet that has been designed and fabricated for years. This research evaluated the effects of different grades of hydrophilic polymers in sustained release of Gliclazide tablets made with direct compression technique. HPC GF GRADE, HPMC K4M, and PARTECK® SRP 80 were used as the polymer, Avicel pH 101 (MCC) was used as the highly compressible diluent and Starch 1500 was used as insoluble tablet filler. Aerosil 300 and Magnesium Stearate was used as a Glidant and lubricant for improving the flow property of powder and to decrease the friction between dying wall and punches. Pre-compression characteristics were evaluated for angle of repose, bulk density, compressibility, tapped density, and Hausner's ratio and DSC, XRD, FT-IR. Tablets were prepared on a rotary tablet press machine (Eliza press) and after compression tablets were evaluated for weight variation, thickness, hardness, friability, drug content, and in-vitro drug release study. The physico-chemical properties of blends were estimated accelerated stability study was also developed formulations were kept for stability study for three months as per ICH guidelines and found to be stable. Advantages of formulating insoluble drugs such as Gliclazide is that if it is used in the preparation of capsules or tablets of the drug, its dose might be reduced which is economically beneficial.
\end{abstract}

Keyword: SR Gliclazide, HPC GF, HPMC K 4M, PARTECK SRP 80, Avicel pH 101, Starch 1500, Aerosil 300, Magnesium stearate, etc. 


\section{Introduction}

Gliclazide is a potential oral hypoglycemic drug useful for the treatment of non-insulindependent diabetes (type 2) mellitus (NIDDM) ${ }^{[1-2]}$ which is a growing global epidemic, especially in Asian populations. Gliclazide is a member of class sulphonylurea which involved insulin secretagogues, which perform by stimulating beta cells of the pancreas to release insulin ${ }^{[10,11]}$. Gliclazide which includes antiglycation effect on in-vitro AGE formulation was demonstrated ${ }^{[3]}$. Gliclazide is best known for reducing fasting plasma glucose, glycosylated hemoglobin (HbA1c) levels (reflective of the last 8-10 weeks of glucose control), and postprandial blood glucose ${ }^{[2]}$. Oral doses of 40 to $120 \mathrm{mg}$ of Gliclazide results in a plasma concentration of 2.2 to $8.0 \mu \mathrm{g} / \mathrm{ml}$ within 2 to $8 \mathrm{hrs}{ }^{[2]}$. Gliclazide has a high protein binding affinity such as an albumin (85 to $97 \%$ ) ${ }^{[2]}$ and mainly binds to site II of the HSA (Human Serum Albumin) molecule with the involvement of the aromatic ring of Tyrosine ${ }^{[4]}$ and high albumin (95\%) binding affinity which helps to enhance its distribution in blood influencing its bio-availability and pharmacokinetics properties.

The half-life of the drug is $10.4 \mathrm{~h}$, duration of action 10-24 hr and firstly extensively metabolized in the liver to form hydroxylated and oxidized derivatives, as well as glucuronic acid conjugates ${ }^{[5-6]}$. The drug reduced solubility in purified water by 0.19 $\mathrm{mg} / \mathrm{mL}$ which is the problem for the biological effect as a result of reduced dissolution and bio-availability ${ }^{[5-6]}$. Gliclazide is characterized by considerable interindividual variability in pharmacokinetics, clinical efficacy, and adverse effects, making the therapy more complicated also and which is helpful for the treatment of Type II Diabetes Mellitus with oral antidiabetes drugs [7]. Gliclazide exhibits variability in pharmacokinetics as its dissolution rate depends on gastric emptying time. Its dissolution varies 1 ) in the small intestine and stomach where it has a different degree of solubility 2) with extensive metabolism in the liver, and 3) with physiological and formulation characteristics ${ }^{[7]}$. The efficacy of Gliclazide as an oral dosage form is its very low aqueous solubility because hydrophobic. Gliclazide belongs to Class II of the Biopharmaceutical Classification System (BCS) in which the drug dissolution rate is the controlling step in drug absorption ${ }^{[7]}$. The slow dissolution of Gliclazide is due to poor wetting of its surface (powder form) by water ${ }^{[8]}$. Currently, Gliclazide formulation does not provide patient compliance since 2-3 tablets 
per day are required to meet the daily therapeutic dose due to its poor solubility and bio-availability. Earlier research indicated that the formulation aimed to enhance the dissolution of Gliclazide, can increase its absorption in $\mathrm{GI}^{[8]}$.

Evaluated the effect of mixing hydrophilic polymers on the release profile of Gliclazide from tablet used hydrophilic polymers HPC GF, HPMC K 4M, and PARTECK SR P-80 polymers which are known for their potential to prolong the release of the drug. In addition, HPC GF has a low water affinity and hence hydrates slowly preventing lumping during the preparation of the sample ${ }^{[13]}$. HPMC K4M (hypromellose) is a highly viscous polymer and thermally gel. Hypromellose provides the release of a drug in a controlled manner and effectively increases the release profile of a drug and prolongs its therapeutic effect ${ }^{[14]}$. Parteck SR $\mathrm{P}-80$ is a new functional polymer based on polyvinyl alcohol (PVA) and has posed a matrix diffusion mechanism that helps to increase bio-availability. Parteck ${ }^{\circledR}$ SR P-80 is highly compatible with the direct compression technique $^{[15]}$. This is aimed to develop Gliclazide tablet in such a way that a single dose can provide the required daily therapeutic dose, thereby increasing patient compliance and reducing cost of the treatment by reducing cost per dose as well as the number of doses.

In this study, tablets of Gliclazide were prepared by direct compression method, with an intention that the sustained release formulation will release the Gliclazide to combat the postprandial hyperglycemic surge followed by a steady-state plasma glucose level controlled by sustained release. The compatibility studies, pre-compression studies, post-compression studies, dissolution studies, and kinetic release profiles were performed ${ }^{[5]}$.

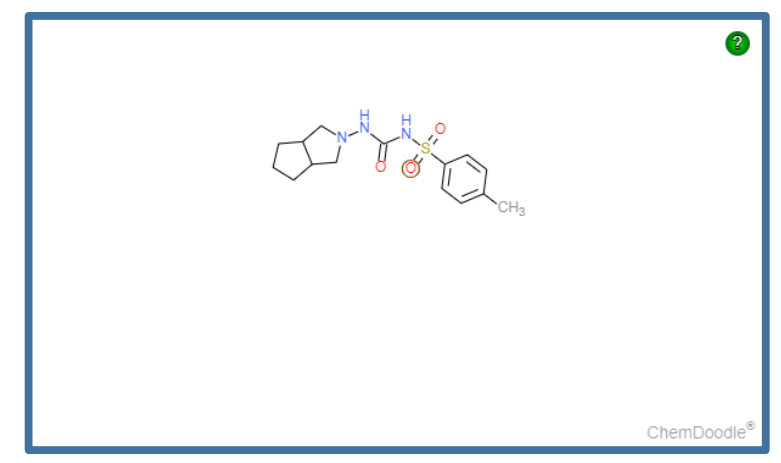

Fig. 1.: Structure of Gliclazide drug ${ }^{[9]}$ 


\section{Experimental:}

Material:

Gliclazide was obtained from Bajaj Healthcare; HPC GF grade polymer was obtained from Ashland (always solving) used for sustained the release of the drug; HPMC $\mathrm{K} 4 \mathrm{M}$ was obtained from Dow used as a ratelimiting polymer; Parteck SRP 80 polymer has obtained from Merck well suited for direct compression processes and accelerates formulation; Avicel pH 101 FMC used as a diluent; Starch 1500 was obtained from Colorcon and; Magnesium stearate was obtained from SD Fine chemical Ltd and used as a lubricant and Aerosil 300 was obtained Evonik and used as Glidant. Acetonitrile and water employed for the preparation of mobile phases were of HPLC grade (Ranked). All the other chemicals and solvents etc., Triethylamine (TEA) and Trifluoroacetic (TFA) were ambient grade ${ }^{\mathrm{s}[27]}$.

\section{Methods:}

\section{Direct Compression Technique:}

The instrument which was used a Rotary press machine (Eliza press) and round shape punches of $8 \mathrm{~mm}$ were used and tablet weight was $200 \pm 7.5 \mathrm{mg}$ Compressed with 10,30 $\mathrm{KN}$ for ejected from the die. Pure drug and diluents and binding agents were passed through 60 mesh sieve and glidant and lubricant were passed through 30 mesh sieve, to improve compressibility and flowability of the material. V-cone-shaped blender (Wintech pharmachem equipment Pvt. Ltd.) This was helpful for uniform mixing of the blend and blended for $10 \min ^{[16,19]}$.

\section{Characterization of Gliclazide drug and Polymers}

Before compression have been taken, granules were examined for their parameters such as Angle of repose was determined by funnel method, Hausner's ratio and Carr's index, tapped density and bulk density was

calculated

Angle of repose $=\tan ^{-1}(\mathrm{~h} / \mathrm{r})$

$\mathrm{Cl}=(\mathrm{TD}-\mathrm{BD}) \times 100 / \mathrm{TD}$

Where TD is tapped density and BD is bulk density, $\mathrm{H}$ is Hausner's ratio, $\mathrm{C}$ is Compressibility $^{[20]}$. 
- Particle Size Distribution by Sieve analyzer:

The size distribution of the granules was determined by sieve analysis. A stack of sieves was arranged in reverse order (the top sieve has the largest screen opening). (20 gm) mass was poured on the top sieve. This stack of sieves was shaken for $15 \mathrm{~min}$. After shaking the material retained on each sieve was weighed. The weight of a sample of each sieve is then expressed as a percentage retained in that particular sieve $\mathrm{e}^{[28]}$.

- Particle size analysis by Malvern particle size analyzer:

Laser diffraction method Mastersizer equipped with $2000 \mathrm{MU}$. Drug powder was dispersed in $500 \mathrm{ml}$ of DW.The amount of suspension required for the value of $\%$ obscuration (10-20\%) of the equipment. Diffraction data was evaluated with respect to the diameter corresponding to $10 \%$ [d $(0.1)], \quad 50 \% \quad[(0.5)], 90 \% \quad[(0.9)]$, which means that $10 \%, 50 \%$, and $90 \%$ (volume distribution) of the measured particle are below the given size. The measurement was performed in triplicate ${ }^{[22]}$.

\section{DSC (Differential Scanning}

Calorimetry): Instruments used (Pyris-6, Perkin-Elmer), 3-5 $\mathrm{mg}$ of drug was placed on the aluminum pan and covered with a lid and crimped using DSC crimper. The crimped pans containing the drug were heated against blank crimped pans from $30^{\circ} \mathrm{C}$ to $300^{\circ} \mathrm{C}$ at the rate of $10^{\circ} \mathrm{C} / \mathrm{min}$ under a nitrogen flow of 17 $\mathrm{ml} / \mathrm{min}$ and endothermic peaks obtained were studied $^{[23]}$.

- Fourier Transform Infrared spectroscopy (FT-IR):

Instruments used IR spectrophotometer (Shimadzu, Japan), The FT-IR spectrum of Gliclazide was recorded in the region of $4000 \mathrm{~cm}^{-1}$ to $700 \mathrm{~cm}^{-1}$. Drug samples were identified for the functional groups present $^{[21]}$.

\section{- X-Ray Diffraction}

Instrument used Shimadzu XRD 6100

(Japan). Cu K $\alpha$ X-Ray source was used with $\mathrm{K}=1.54 \mathrm{~A}^{0}$ with the filter of $\mathrm{Ni}$. The $40 \mathrm{KV}$. Voltages with the current $2 \Theta \mathrm{Ma}$ were set. The $40 \mathrm{KV}$ voltages with a current of $2 \Theta \mathrm{Ma}$ were set. Scanning rate $1 \%$ min for $2 \Theta$ for $2-70^{\circ[21]}$. 
Initial studies of batches

Table 1 Formulation with different composition

\begin{tabular}{|c|c|c|c|c|c|c|c|c|c|}
\hline $\begin{array}{l}\text { Batc } \\
\text { h }\end{array}$ & $\begin{array}{l}\text { GLICLAZI } \\
\text { DE }\end{array}$ & $\begin{array}{l}\text { HPC } \\
\text { GF }\end{array}$ & $\begin{array}{l}\text { AVICE } \\
\text { L } \quad \text { PH } \\
101\end{array}$ & $\begin{array}{l}\text { HPM } \\
C \quad K \\
4 M\end{array}$ & $\begin{array}{l}\text { PARTE } \\
\text { CK } \\
\text { SRP 80 }\end{array}$ & $\begin{array}{l}\text { STARC } \\
\text { H } 1500\end{array}$ & $\begin{array}{l}\text { MG. } \\
\text { STEARATE }\end{array}$ & $\begin{array}{l}\text { AEROSIL } \\
\mathbf{3 0 0}\end{array}$ & $\begin{array}{l}\text { TOTA } \\
\text { L }\end{array}$ \\
\hline G01 & 30 & 60 & 8 & - & - & & 1 & 1 & 100 \\
\hline G02 & 30 & 15 & 53 & - & - & & 1 & 1 & 100 \\
\hline G03 & 30 & - & - & 30 & - & 38 & 1 & 1 & 100 \\
\hline G04 & 30 & - & - & 60 & - & 8 & 1 & 1 & 100 \\
\hline G05 & 30 & - & - & 15 & - & 53 & 1 & 1 & 100 \\
\hline G06 & 30 & - & - & - & 60 & 8 & 1 & 1 & 100 \\
\hline G07 & 30 & - & - & - & 15 & 53 & 1 & 1 & 100 \\
\hline G08 & 30 & - & - & - & 30 & 38 & 1 & 1 & 100 \\
\hline G09 & 30 & 30 & 38 & - & - & - & 1 & 1 & 100 \\
\hline G10 & 30 & - & - & 60 & - & 8 & 1 & 1 & 100 \\
\hline G11 & 30 & 30 & - & - & - & 38 & 1 & 1 & 100 \\
\hline G12 & 30 & 60 & - & - & - & 8 & 1 & 1 & 100 \\
\hline G13 & 30 & - & 53 & - & 15 & - & 1 & 1 & 100 \\
\hline
\end{tabular}

\section{- In-Vitro Dissolution study:}

An In-vitro drug release of Gliclazide tablets was studied by, using dissolution apparatus IIpaddle (Electrolab Model TDT 08, India) as per the in-house developed method. $900 \mathrm{~mL}$ of $\mathrm{pH}$ 7.4 Phosphate buffer as the dissolution medium was placed in the dissolution vessels, and the temperature was maintained to $37 \pm$ $0.5^{\circ} \mathrm{C}$. The rotation speed of the paddle was $75 \mathrm{rpm}$. At predetermined time intervals (2, 6, 12, 16, and 24 hours), $10 \mathrm{~mL}$ of dissolution medium was removed for determining a drug concentration and a fresh medium was replaced. The amount of Gliclazide released in the dissolution medium was measured using a UV Spectrophotometer at the wavelength of $226 \mathrm{~nm}$. The dissolution study was performed using 6 tablets in triplicate $[12,20]$. 


\section{Post compression parameter of tablets}

The properties of compressed tablets, such as weight variation friability hardness, an assay of the tablets, and content uniformity were determined. Hardness was determined by using Monsanto hardness tester and it is expressed in $(\mathrm{kg} / \mathrm{cm} 2)$ or N. Friability was determined by using Roche friability testing apparatus tumbling that revolves at $25 \mathrm{pm}$. After 4 min. Weight variation and content uniformity of drug content was performed according to USP procedures ${ }^{[20]}$.

\section{Results and Discussion:}

Characterization of the drug:

Table 2 Flow properties of polymer and Gliclazide Drug

\begin{tabular}{|l|l|l|l|l|l|}
\hline $\begin{array}{l}\text { Sr. } \\
\text { No }\end{array}$ & Properties & $\begin{array}{l}\text { HPC GF } \\
\text { GRADE }\end{array}$ & HPMC K 4M & $\begin{array}{l}\text { PARTECK SR } \\
\text { P-80 }\end{array}$ & $\begin{array}{l}\text { Gliclazide } \\
\text { Drug }\end{array}$ \\
\hline 1 & Angle of Repose & $18.24^{\circ} \mathrm{C}$ & $20.21^{\circ} \mathrm{C}$ & $17.94^{\circ} \mathrm{C}$ & $14.41^{\circ} \mathrm{C}$ \\
\hline 2 & Bulk density $(\mathrm{g} / \mathrm{ml})$ & $0.4 \mathrm{~g} / \mathrm{ml}$ & $0.50 \mathrm{~g} / \mathrm{ml}$ & $0.5 \mathrm{~g} / \mathrm{ml}$ & $0.555 \mathrm{gm} / \mathrm{ml}$ \\
\hline 3 & Tapped density & $0.5 \mathrm{~g} / \mathrm{ml}$ & $0.70 \mathrm{~g} / \mathrm{ml}$ & $0.909 \mathrm{~g} / \mathrm{ml}$ & $0.769 \mathrm{gm} / \mathrm{ml}$ \\
\hline 4 & Hausner's ratio & 1.25 & 1.4 & 1.8 & 1.385 \\
\hline 5 & Compressibility Index & $20 \%$ & $28.57 \%$ & $44.99 \%$ & $27.82 \%$ \\
\hline 6 & Moisture content $(\%)$ & $5.545 \%$ & $4.230 \%$ & $4.710 \%$ & $1.992 \%$ \\
\hline
\end{tabular}

The flow properties of Gliclazide drug exhibited bulk and tapped density 0.555 and $0.769 \mathrm{gm} / \mathrm{ml}$. Angle of repose was found $14.41^{\circ} \mathrm{C}$ indicating very good flow and compatibility.Compressibility Index and Hausner's ratio, Moisture Content was found $27.82 \%, 1.385$ and $1.992 \%$. indicating the good flow properties and less moisture content. The flow properties of the polymer were presented in Table 2. The angle of repose of the polymers showed excellent flowability and compatibility range from (25 $<$ angle of repose < 30). Bulk and tapped density was found in the range of 0.4 to $0.5 \mathrm{gm} / \mathrm{ml}$ and 0.5 to $0.9 \mathrm{gm} / \mathrm{ml}$. Compressibility Index and Hausner's ratio of the polymers were exhibited that between $20.0 \%$ to $45 \%$ and more than 1.25 respectively, confirming the poor flow of polymer and more moisture content ${ }^{[20]}$. 


\section{Particle Size Distribution Analysis(Sieve Analysis)}

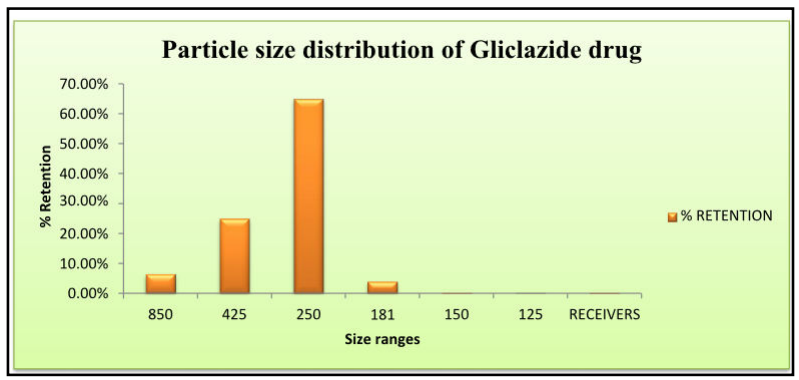

Fig. 2 Particle size distribution of Gliclazide drug by Sieve Analysis Instruments.

The flow properties of powders are dependent upon the particle size distribution as well as particle shape. The particle size of the drug was 250 micron $^{\mathrm{s}}{ }^{[28]}$.

\section{Particle Size Distribution Analysis (Mastersizer MU 2000)}

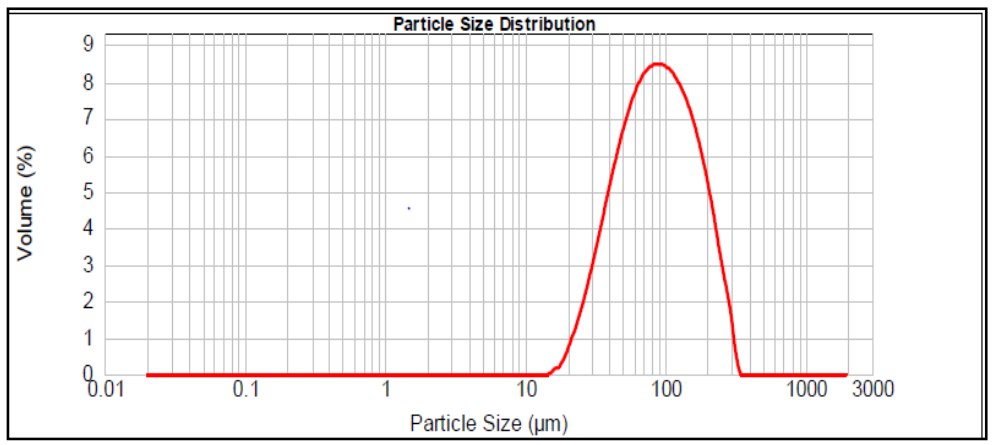

Fig. 3 Mastersizer MU 2000

The flow properties of powders are dependent upon the particle size distribution as well as particle shape. Asymmetric particles have poor flow characteristics and drug and other additives into particles of uniform size have good flow properties. Particle size of drug is $d(0.9)=196 \mu \mathrm{m}, \mathrm{d}(0.5)=87.24 \mu \mathrm{m}, \mathrm{d}(0.1)=36.71$ $\mu \mathrm{m}^{[22]}$. 
Determination wavelength maximum absorbance $(\chi \max )$ of Gliclazide in $7.4 \mathrm{pH}$ phosphate buffer and methanol.

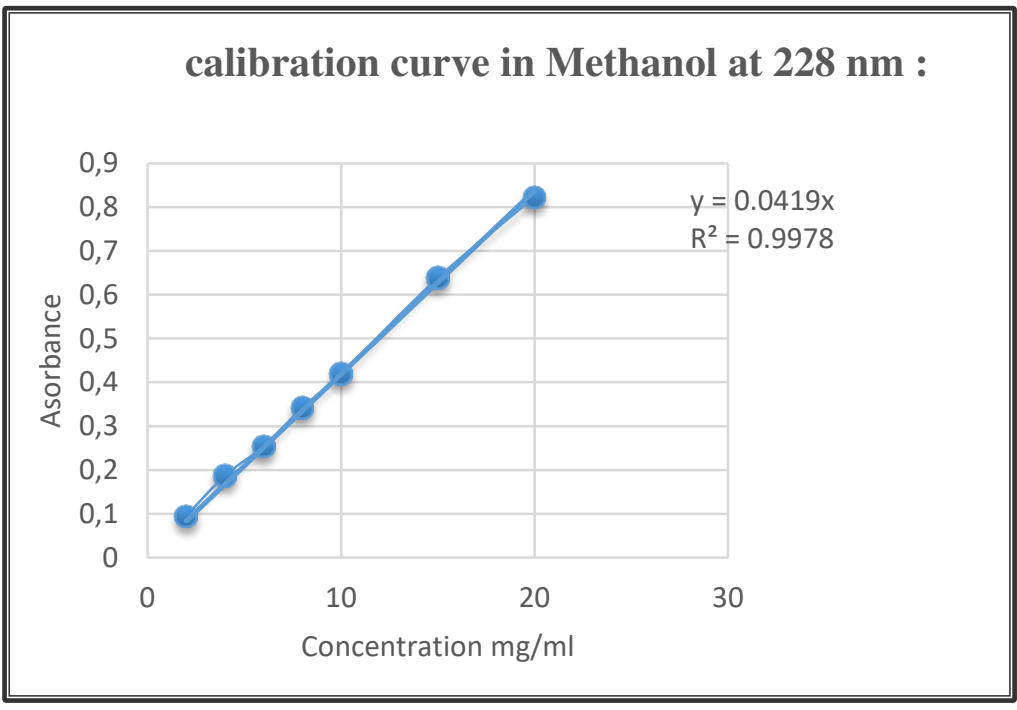

Fig.4 Linearity curve of 7.4 pH Methanol solution.

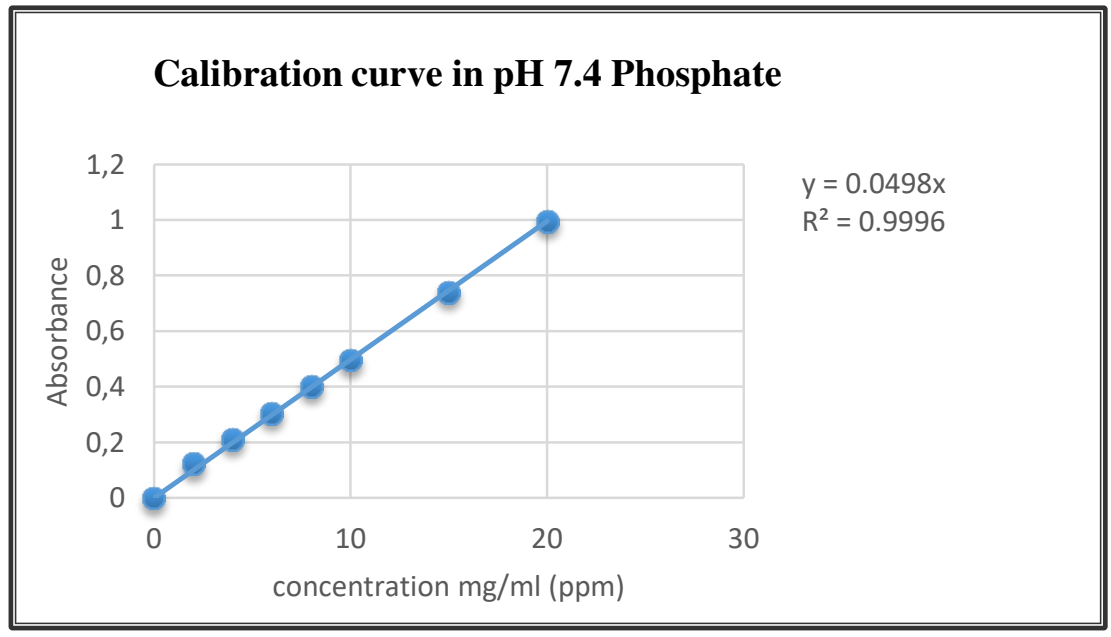

Fig. 5 Linearity curve of $7.4 \mathrm{pH}$ phosphate buffer solution.

The Calibration curve of Gliclazide was obtained by using UV 2600 Shimadzu. Gliclazide has solubility in methanol and $7.4 \mathrm{pH}$ phosphate buffer solution. According to ICH guidelines Q2 R1, the linearity was repeated in duplicate at 226 and $228 \mathrm{~nm}$, and the linearity ranges were confirmed with an $\mathrm{R}^{2}$ of 0.9996 and 0.9978. The linear regression equation was $\mathrm{Y}=0.0498, \mathrm{Y}=0.0419$. 


\section{DSC (Differential Scanning Calorimetry)}

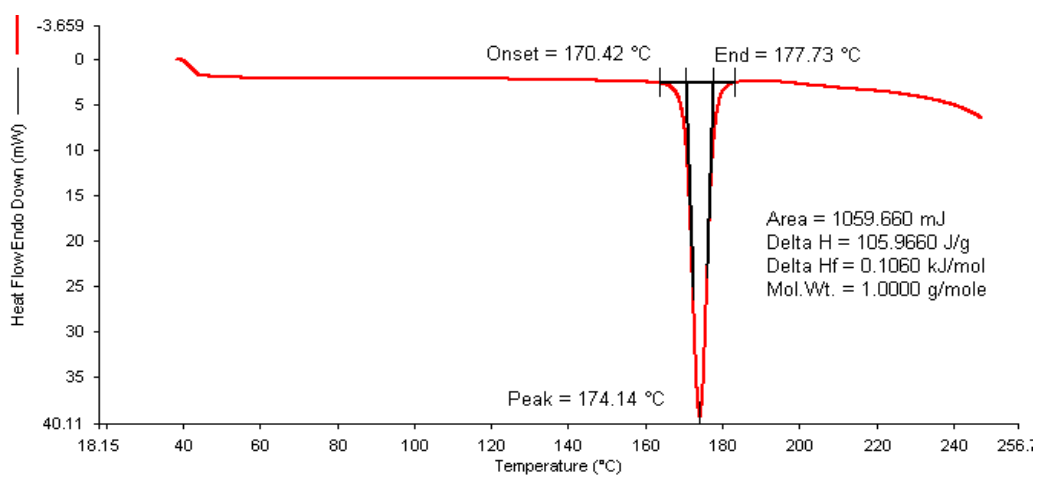

Fig.6 DSC (Differential scanning Calorimetry) Of Gliclazide drug

In DSC were used Perkin Elmer instrument for Gliclazide shows an endothermic process and its melting peak of crystalline Gliclazide is $174.14^{\circ} \mathrm{C}^{[23]}$.

\section{FTIR (Fourier - Transform Infrared Spectroscopy)}

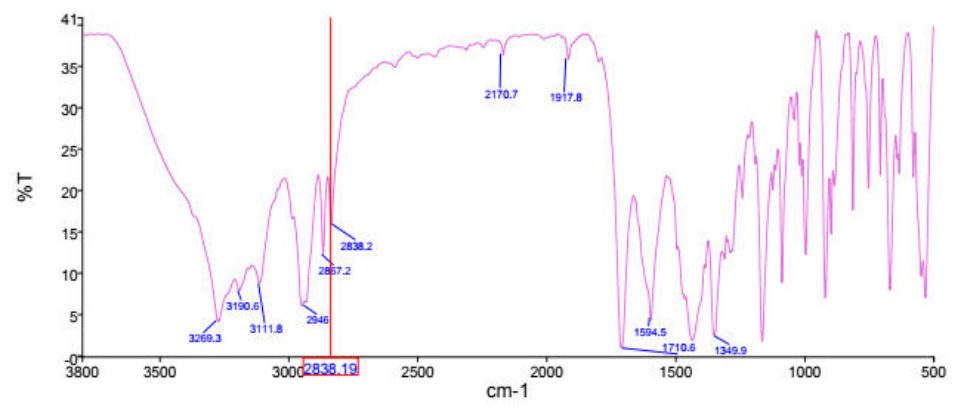

Fig.7 FTIR (Fourier-transform infrared spectroscopy) of Gliclazide drug

Perkin Elmer FT-IR-6600 instrument was used for the study. FTIR spectra of pure Gliclazide drug showed peaks at $1710.46 \mathrm{~cm}^{-1}$ (Carbonyl sulphonylurea group) and $3274.34 \mathrm{~cm}^{-1}$ (-NH Stretch) and $1349 \mathrm{~cm}^{-1}$ and $1162 \mathrm{~cm}^{-1}$ (Sulphonylurea group band) respectively ${ }^{[17,21]}$. 


\section{X-Ray Diffraction:}

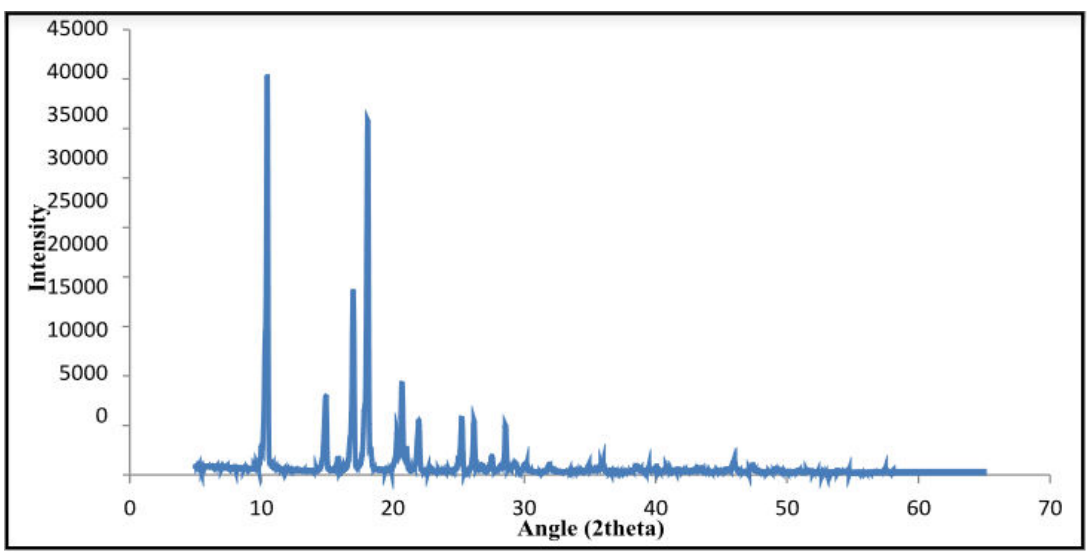

Fig.8 X- Ray Diffraction of pure Gliclazide

X-ray Diffraction was used Shimadzu Lab XRD-6100 instrument pattern of Gliclazide exhibited $10^{\circ} \mathrm{C}$ and $17^{\circ} \mathrm{C}$ while the sharp, highly intense, and less diffused peaks indicating the crystalline nature of the drug, while peaks at $15^{\circ} \mathrm{C}, 20^{\circ} \mathrm{C}, 25^{\circ} \mathrm{C}$, and $26^{\circ} \mathrm{C}$ were short peak. The intensity of XRD peaks of the drug, physical mixtures, and solid dispersion was recorded ${ }^{[21]}$.

- Evaluation DSC (Differential scanning Calorimetry ) of polymers
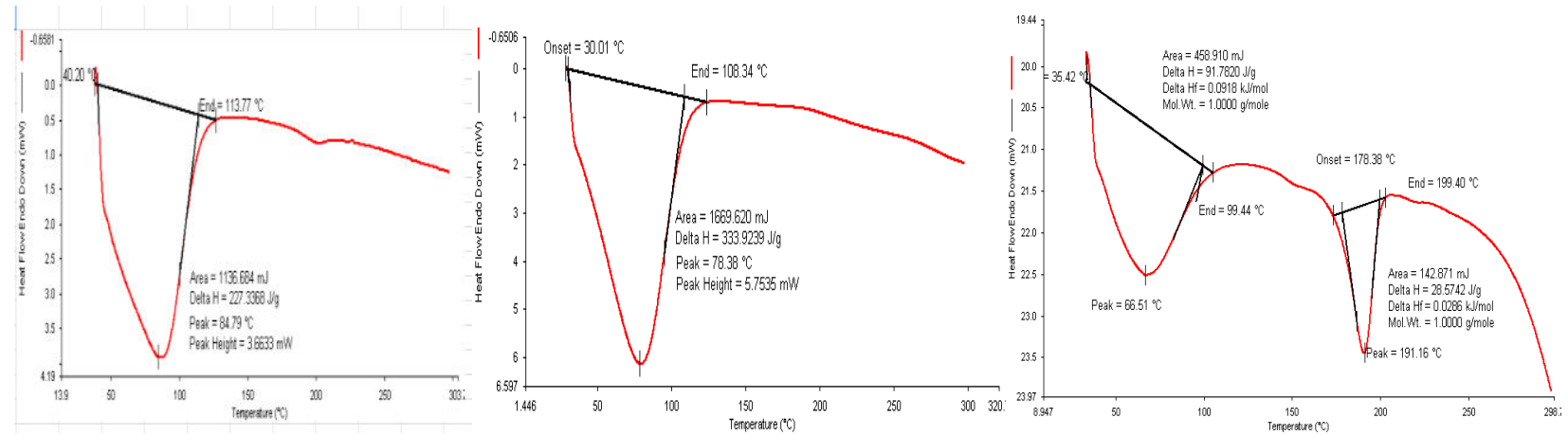

Fig.9 (Differential scanning Calorimetry) Of HPC GF GRADE AND HPMC K4M, PARTECK SR P -80 Polymer

Thermal stabilities and oxidative stabilities of the polymers were evaluated, using differential scanning calorimetry. PARTEK SR P-80 show Endothermic first peak at $66.51^{\circ} \mathrm{C}$ and $191.16^{\circ} \mathrm{C}$ thermal stability and oxidative stability of polymer. ${ }^{[23]}$. 
- FTIR ( Fourier-transform infrared spectroscopy) of polymers

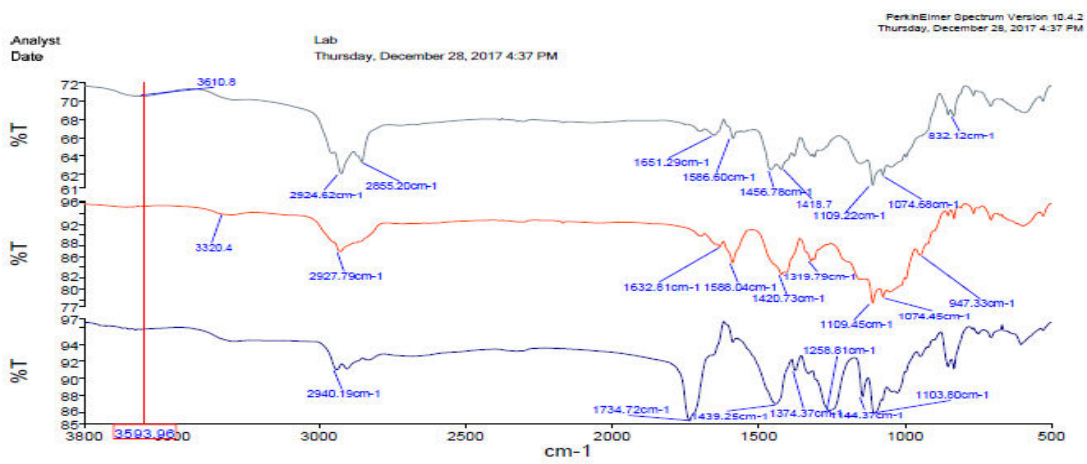

Fig.10 FT-IR OF HPC GF GRADE AND HPMC K4M, PARTECK SR P -80 POLYMERS

HPC GF GRADE POLYMER indicates that $2940.19 \mathrm{~cm}-1$ is $(\mathrm{C}-\mathrm{H})$ stretch $1734.72 \mathrm{~cm}-1$ is carbonyl group present. HPMC k4M indicate 2927.79 is $(\mathrm{C}-\mathrm{H})$

stretch and $1632.8 \mathrm{~cm}-1$ is $(\mathrm{C}=\mathrm{C})$ stretch. PARTECK SR P -80 is $2924.62 \mathrm{~cm}-1$ is $(\mathrm{C}-\mathrm{H})$ and $1651.29 \mathrm{~cm}-$ 1 is $(\mathrm{C}=\mathrm{C}) \operatorname{stretch}^{[21,25]}$.

Table 3 Post - Compression parameter

\begin{tabular}{|l|l|l|l|l|}
\hline Sr. No. & Weight Variation & Thickness & Hardness & Friability \\
\hline 1 & Range $200 \pm 7.5$ & $3 \mathrm{~mm}-4 \mathrm{~mm}$ & $7-12 \mathrm{~kg} / \mathrm{cm}^{2}$. & Less than $1 \%$ \\
\hline
\end{tabular}

Weight variations of Gliclazide $30 \mathrm{mg}$ tablet range $200 \pm 7.5$ (8mm and concave round shape punch).

Friability less than $1 \%$ and weight variation within acceptable limits and a tablet hardness range of 7-12 $\mathrm{kg} / \mathrm{cm}^{2}$, the thickness of tablets was between range of 3-4 mm. Overall, the tablet with the reduced weight and dimensions and with improved hardness and friability have been achievable by performing sustained released tablet by using various combinations of drug and polymer ratio ${ }^{[20]}$.

\section{DSC of Formulations of HPC GF, HPMC K4M, PARTECK SRP 80}
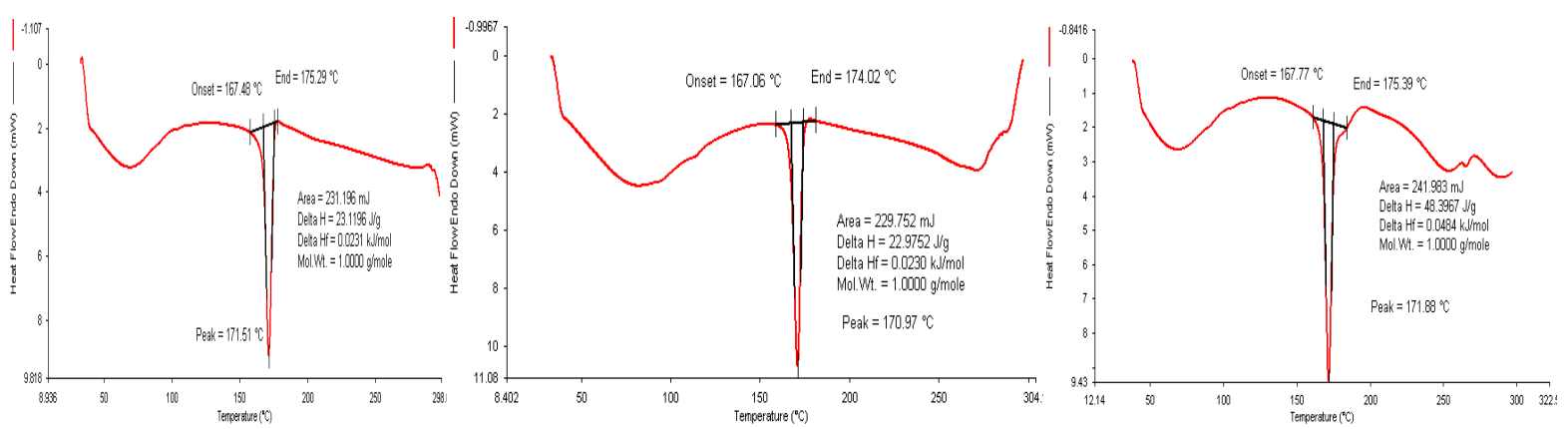
Fig.11 Differential scanning calorimetry of formulations of polymers

Results of DSC analysis of formulation batches of HPC GF, HPMC K4M, PARTECK SRP 80 batches found that the polymer and drug are compatible with each other and there is no reaction between the polymer and drug ${ }^{[23]}$.

\section{Fourier-transform infrared spectroscopy of drug and polymer}

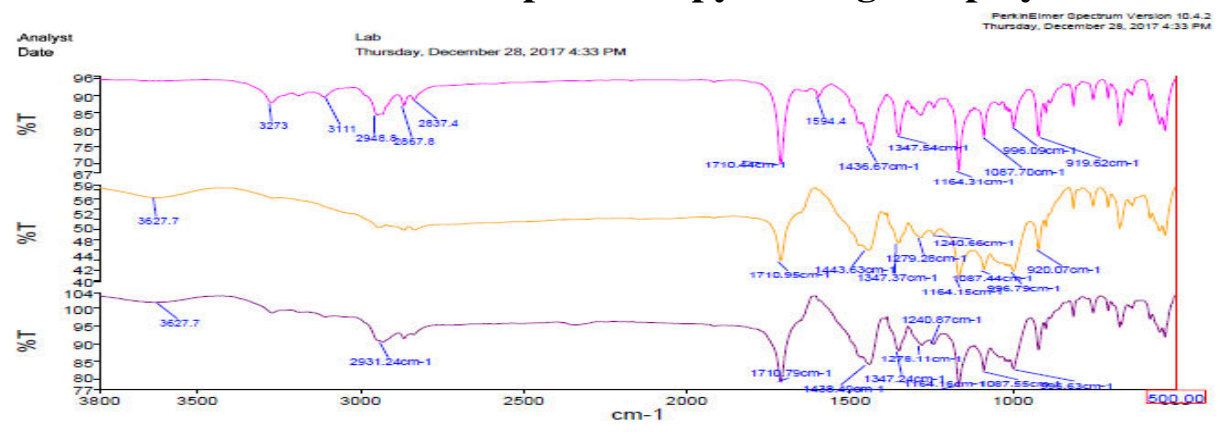

Fig. 12 Fourier-transform infrared spectroscopy of drug and polymers

The compatibility between the polymer and drug is evaluated using Infra-red Spectroscopy. IRS of the batch G1 formulation as shown in Figure indicates that $2931.24 \mathrm{~cm}-1$ is $(\mathrm{C}-\mathrm{H})$ stretch $1710.79 \mathrm{~cm}-1$ is carbonyl group present. HPMC k4m indicate 2927.79 is $(\mathrm{C}-\mathrm{H})$ stretch and $1710.95 \mathrm{~cm}-1$ is $(\mathrm{C}=\mathrm{C})$. Parteck SR P -80 is $2948.8 \mathrm{~cm}-1$ is $\mathrm{C}-\mathrm{H}$ stretch and $1710.44 \mathrm{~cm}-1$ is $(\mathrm{C}=\mathrm{C}) \mathrm{stretch}^{[21,25]}$.

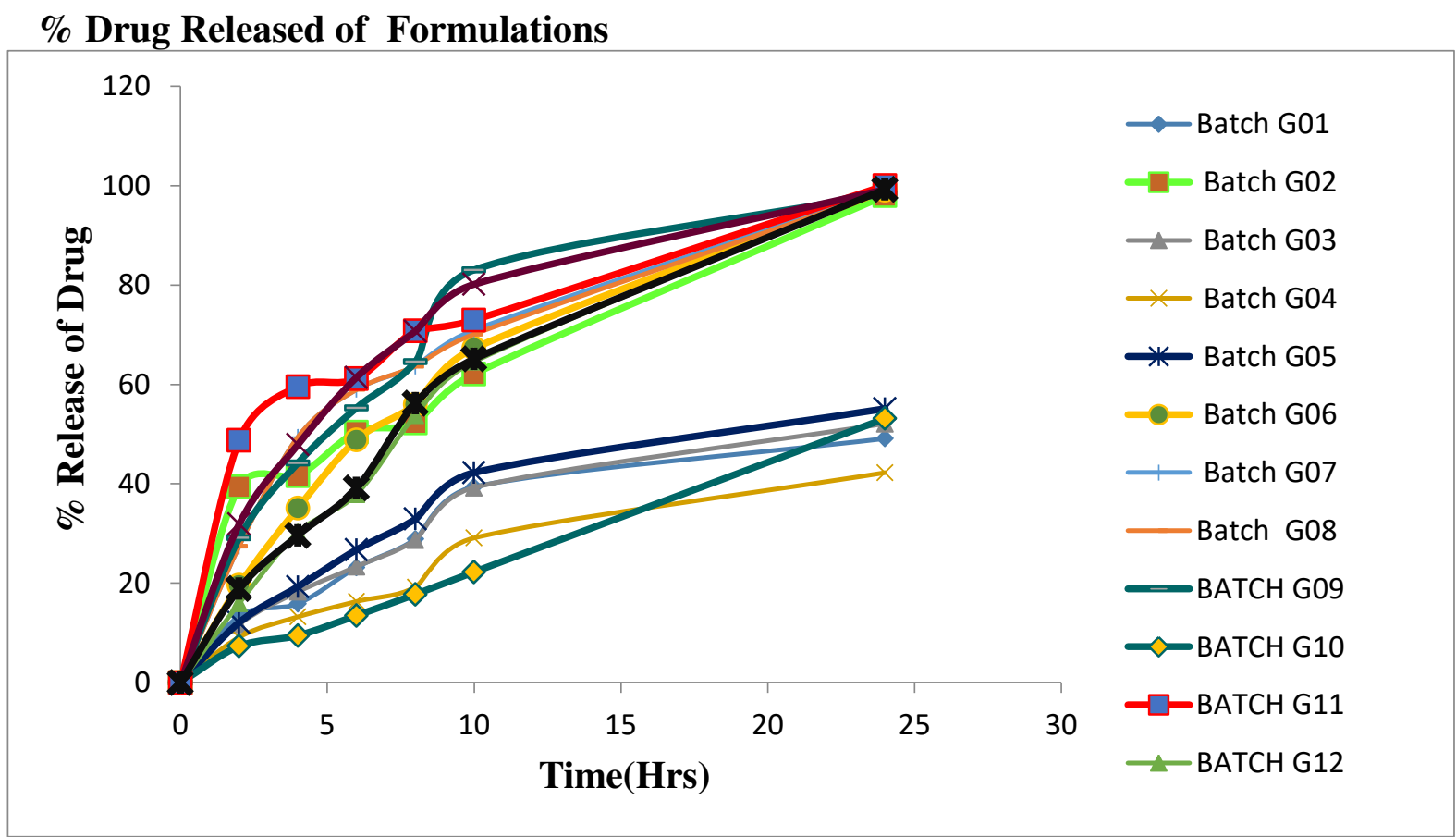

Fig. 13\% Released of Drug Formulations 
Ideally, Gliclazide tablets should be sustained the release of the drug to maintain an effective drug plasma concentration from the in-vitro drug dissolution profile of Gliclazide matrix tablets. It was found that after 2 hrs results of formulation batches G01, G02,G03,G04,G05,G06, G07,G08,G09,G10,G011,G12,G13 were $13.38 \%, 39.4 \%, 11.72 \%, 9.14 \%, 12.12 \%$, $19.59 \%, \quad 27.48 \%, 27.48 \%, 29.14 \%, \quad 7.33 \%$, $48.77 \%, 15.95 \%, 31.9 \%$ of the drug was released till 2 hrs.from all batches ${ }^{[26]}$. During 1 to $2 \mathrm{hrs}$, the marketed formulations percentage released was found to be $8-25 \%$. After the 2 hrs more than $30 \%$ to $60 \%$ up to 8 hrs drug was released. After $8 \mathrm{hrs}$. the released rate increases slightly and a sustained released pattern was observed for $24 \mathrm{hrs}$. The formulation of G02, G06, G07, G08, G09, G012, observed. that the release profile was found to be biphasic with an initial burst effect in the first hour and then the release was slow and extended up to $24 \mathrm{~h} .{ }^{[18,29]}$

\section{Conclusion}

The oral route of administration for sustained release drug delivery system increases the efficiency of the dose, more flexibility, reduced dose frequency, and better patient compliance. It depends upon the physic ochemical properties of the drug, type of
In such an instance higuchi release is desirable, where the release rate is fast in initial conditions and the release rate will become slower as the time progress and concentration always be maintained within saturation level at the site of absorption and thus produces greater bio-availability ${ }^{[24,29]}$. The proposed method is simple and does not involve laborious time-consuming. Formulation G02, G06, G07, G08, G09, and G012 (containing $30 \mathrm{mg}$ of Gliclazide had shown drug release over 24 hours. Formulation G08 is a better system for the once-daily therapy of Gliclazide. From the drug content, post-compression parameters, in-vitro drug release studies it was found that among the various formulations, Formulation G08 (Drug with Parteck SR P-80) was the found to be the best formulation. The formulation was further taken for pilot scaleup studies and stability studies.

delivery system, the disease being treated, patient condition and treatment duration, presence of food, gastrointestinal motility, and administration of other drugs.

In the present study, we attempted to develop Gliclazide sustained-release tablet based on 
HPMC K4M, HPC GF, PARTEK SRP 80 polymer. Since Gliclazide is having a long biological half-life duration of action is 10-24 hours. The tablets were prepared successfully by direct compression technique by using HPMC K4M, HPC GF, PARTEK SRP 80 polymer, The concentration of binder in the formulation was more effective for formulating tablets had acceptable characteristics $^{[18]}$. Gliclazide having the maximum absorbance at $228 \mathrm{~nm}$, the drug content was analyzed by a sensitive and reproducible UV-Spectro-photometer method developed in our laboratory as explained in the experimental part. The drug content of the tablet was uniform and within acceptable limits. The physico-chemical parameters like thickness, hardness, friability, and weight variation of formulated tablets were within the standard limits of united States Pharmacopoeia ${ }^{[29]}$ From the above discussion, we can conclude that Moreover; the reasonable cost of oral Sustained release drug delivery system has lead ease of market penetration as replacement of oral conventional drug delivery system.

\section{References:-}

1. Hong S.S, Lee S.H, Lee Y.J, Chung S.J, Lee M.H, Shim S.K: Accelerated oral absorption of Gliclazide in human subjects from a soft gelatin capsule containing a peg 400 suspension of Gliclazide, J. Control. Release (1998) 51; 185-192.

2. Sarkar A, Tiwari A, Bhasin P.S, Mitra M.: Pharmacological and pharmaceutical profile of Gliclazide: a review, J. Appl. Pharm. Sci (2011) 09; 11-19.

3. Weiguo Li, Kimiko Ota, Nakamura, Naruse Keiko, Nakashima, Hamada Yoji: Brief Communication: Antiglycation effect of Gliclazide on in vitro AGE formation from glucose and methylglyoxal, Exp. Biol. Med (2008) 233; 176-179.

4. Seeder N, Kanojia M: Reversible binding of antidiabetic drugs, repaglinide, and gliclazide, with human serum albumin, Chem. Biol. Drug Des. (2008) 72; 290-296.

5. Purushottam S, Gangane, Manish M, Kadam, Debarshikar, Mahapatra, Nilesh M, Mahajan, and Ujwala N, Mahajan: Design and formulating Gliclazide solid dispersion immediate-release layer and metformin sustained release layer in bilayer tablet for the effective postprandial management of diabetes mellitus, Int. J. Pharm. Sci, (2018) 9(9): 3743-3756. 
6. Palmer KJ and Brogden RN: Gliclazide. An update of its pharmacological properties and therapeutic efficacy in non-insulin-dependent diabetes mellitus, Drugs (1993) 46(1): 92-125.

7. Kim H, Yun M, Kwon K.I: Pharmacokinetic and pharmacodynamic characterization of gliclazide in healthy volunteers, Arch. Pharm. Res. (2003) 26: 564-568.

8. Shaik, M., Shaik, S. and Kilari, E.K: Population pharmacokinetics of gliclazide in normal and diabetic rabbits, Biopharm Drug Dispos, (2018) 39: 265-274.

9. Gopal Venkatesh Shavi, Averineni Ranjith Kumar, Yogendra Nayak Usha, Karthik, Arumugam, Sureshwar Pandey, Nayababhirama Udupa: Enhanced dissolution and bioavailability of Gliclazide using solid dispersion technique, Int. J. Drug Deliv. (2010) 2: 49-57.

10. Udaykumar Rao B, Anna Pratima Nikalje: Determination of gliclazide in a tablet dosage form in the presence of metformin hydrochloride by ion-pair -reversed-phase liquid chromatographic technique, Afr. J. Pharm. Pharmacol. (2011) 5(11): 1331-1337.

11. Ali Mohammad Almousa, Mohammed Navy Alruwaily, Abdullatif Abdul Aziz, Alarifi, Habeeb: Situation Analysis Of Diabetic Patients At Primary Health Care
Centre College Of Medicine, J Med Diagn Meth. (2017) 6: 2-6.

12. Vijayalakshmi, P, Devi, V.K, Devi, K, Benson, M.K, and Srinagesh S: Formulation development and in vivo characterization of solubility enhanced gliclazide tablets, Curr Trends Biotechnol Pharm. (2008) 2: 456-461.

13. Durig T, Lusvardi K.M, Harcum W.W: Hydroxyl propyl cellulose in Modified Release Matrix Systems: Polymer Molecular Weight Controls Drug Release Rate and Mechanism, Pharmaceutical technology report, Pharm. Technol. (2011): 1-7.

14. Fukui S, Yano H, Yada S, Mikkaichi T., and Minami H: Design, and evaluation of an extended-release matrix tablet formulation the combination of hypromellose acetate succinate and hydroxypropyl cellulose, Asian J. Pharm. Sci. (2017) 12: 149-156.

15. Han X.W, Zhang H.W, Luo H.Y, Zheng X.L, Yang Z, Liao Y.J, Yang: Preparation of Poly(vinyl alcohol) microspheres based on droplet microfluidic technology, Chinese J. Anal. Chem. (2018) 46: 1269- 1274.

16. Chowdary, K.P.R and Ramya K: Recent research on co-processed excipients for direct compression a review, Pharmacie Globale, Int J. compr. Pharm. (2013) 4: 1.

17. Sanjay K. Sharma, Shailendra Mohan and Manish Jaimini, Formulation and in vitro evaluation of modified release tablets of 
gliclazide (anti-diabetic drug), Int. J.Pharm. Pharm, (2014) 6(2): 259-261.

18. Muniyandy Saravanan, Kalakonda Srinatarj, and Kettavarampalayam Swaminath Ganesh: The effect of tablet formulation and hardness on in vitro release of cephalexin from eudragit L100 based extended-release tablets, Biol. Pharm. Bull. (2002) 25(4) 541545 .

19. Gulshan Bansal, Manjeet Singh Kaur: Forced degradation study on gliclazide and application of validated stability-indicating HPLC-UV method instability testing of gliclazide tablets, Chromatographia (2007) 66:751-755.

20. Chandan Garg and Vikrant Saluja: Oncedaily sustained-release matrix tablets of metformin hydrochloride based on an enteric polymer and chitosan, J Pharm Educ Res. (2013) 4: 95-97.

21. Anshuman Keshari, Dr.Pushpendra Kumar Tripati, Arjita Srivastava, Ratan Vishwas: formulation and evaluation of effervescent floating tablets of the antidiabetic drug, J. drug deliv. ther. (2015) 5(6): 43-55.

22. Eshel G, LevyG.J, Mingelgrin U, and Singer M.J: Critical Evaluation of the Use of Laser Diffraction for Particle-Size
Distribution Analysis, Soil Sci. Soc. Am. J. (2004) 68:736-743, https://doi.org/10.2136/sssaj2004.7360.

23. Michael M. Crowley, Britta Schroeder, Anke Fredersdorfb, Sakae Obarac, Mark Talaricod, Shawn Kuceraa, James W, McGinitya: Physicochemical properties and mechanism of drug release from ethylcellulose matrix tablets prepared by direct compression and hot-melt extrusion, Int. J. Pharm. (2004) 269: 509-522, DOI: 10.1016/j.ijpharm.2003.09.037

24. .Indian S. Pather, Irina Russel, James A, Syce A, Steven H, Neau: Sustained release theophylline tablets by direct compression and formulation and in vitro testing, Int. J. Pharm. ( 1998) 64: 1-10.

25. Nunthanid J, Laungatanaanan $\mathrm{M}$, Sriamornsak $\quad \mathrm{P}, \quad$ Limmatvapirat, Puttipitatkhachorn S, Lim L.Y: Characterization of chitosan acetate as a binder for sustained released tablets, J Control Release. (2004) 99, 15-26.

26. Prithiviraj Anand, Kesavan Bhaskar, Somasundaram, Ramchandran, Muniyandy Saravanan, and Radhakrishnan Vinod: Eudragit NE30D based metformin/gliclazide extended-release tablets: formulation, 
characterization and in vitro release studies, chem. pharm. bull.(2002) 50:1495-1498.

27. Aradhana K, Pillai K.V, Khileshwari Gautam, Archana Jain, Krishna K, Verma, Headspace in-drop derivatization of carbonyl compounds for their analysis by highperformance liquid chromatography diode array detection, Anal Chim Acta,(2008) 632:208-215, DOI:10.1016/j.aca.2008.11.021 28. Sarang Oka, Heather Emady, Ondrej Kaspar, Viola Tokarovac Fernando Muzzioa Frantisek Stepanek Rohit Ramachandran The effects of improper mixing and preferential wetting of active and excipient ingredients on content uniformity in high shear wet granulation, Powder Technol. (2015),266277 , https://doi.org/10.1016/j.powtec.2015.03.018. 29. Hussain, T. Saeed, A, Mumtaz M, Javaid Z, Abbas K, Awais A, Idrees H.A, Effect of two hydrophobic polymers on the release of Gliclazide from their matrix tablets, Acta Pol Pharm., (2013) 70: 749-757. 